Rev. Adm. Saúde (On-line), São Paulo, v. 21, n. 83: e296, abr. - jun. 2021, Epub 28 mai. 2021 http://dx.doi.org/10.23973/ras.83.296

PERSPECTIVAS

\title{
Gestão e sustentabilidade econômico-financeira em empresas de oftalmologia
}

Management and economic and financial sustainability in ophthalmology companies

\author{
Cláudio Augusto Junqueira de Carvalho', Luciana Carvalhais de

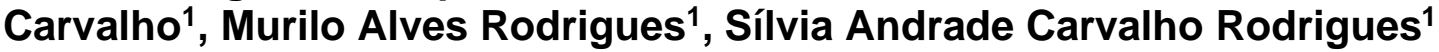

1. Médico oftalmologista. Membro do corpo clínico do Centro Oftalmológico de Minas Gerais, Belo Horizonte MG

\section{RESUMO}

A sustentabilidade, conceito tradicionalmente associado à preservação do meio ambiente em benefício de gerações futuras, hoje, liga-se também aos objetivos de manutenção econômico-financeira da própria organização. Alinhamento de processos, visão corporativa, desenvolvimento de cultura, uso de indicadores para medição de resultados, adaptabilidade do planejamento e metas, manutenção da contabilidade dentro dos critérios de boas práticas, difusão interna de conhecimento e abertura para inovações são os fundamentos mais importantes para a sustentabilidade econômico-financeira. Além disso, ter um olhar social, retribuir a sociedade os bons resultados é sustentabilidade no seu conceito mais nobre. Para ser competitiva, a organização precisa se tornar sustentável. Em saúde, o atual desafio para se manter é conhecer seus custos, para que se possam reduzi-los sem prejuízo na entrega. Esse é o grande desafio para ser competitivo: agregar valor à entrega. Na oftalmologia, os honorários médicos nem sempre são somados ao resultado da empresa, o fluxo de caixa é confundido com lucro e traz problemas sérios à saúde financeira, a dedicação do profissional de saúde é posta acima valendo mais 
um hospital equipado que um resultado financeiro positivo, o amor exagerado dos médicos pelos próprios interesses gera uma dificuldade grande de trabalhar em equipe, entre outros motivos, estes têm impedido o crescimento das clínicas e mesmo levado ao seu encerramento. Resultados sustentáveis associados à boas práticas preparam as empresas para tempos de crise, como a do coronavírus, e preparam para novos desafios, como o mercado de aquisições e fusões, superaquecido.

Palavras-chave: sustentabilidade; administração em saúde; oftalmologia

\begin{abstract}
Sustainability, a concept traditionally associated with preserving the environment for the benefit of future generations, today is also linked to the organization's economic and financial maintenance objectives. Process alignment, corporate vision, culture development, use of indicators to measure results, adaptability of planning and goals, keeping accounting within the criteria of good practices, internal dissemination of knowledge and openness to innovations are the most important foundations for the economic and financial sustainability. In addition, having a social view, giving society good results is sustainability in its most noble concept. To be competitive, the organization needs to become sustainable. In health, the current challenge to maintain is to know your costs, so that you can reduce them without prejudice to delivery. This is the great challenge to be competitive: add value to delivery. In ophthalmology, medical fees are not always added to the company's results, the cash flow is confused with profit and brings serious problems to financial health, the dedication of the health professional is put above worth an equipped hospital rather than a positive financial result , the doctors' exaggerated love for their own interests creates a great difficulty to work as a team, among other reasons, these have impeded the growth of clinics and even led to its closure. Sustainable results associated with good practices prepare companies for times of crisis, such as the coronavirus, and prepare for new challenges, such as the overheated acquisitions and mergers market.
\end{abstract}

Keywords: sustainability; health administration; ophthalmology

\title{
Introdução
}

A sustentabilidade, parte integrante da estratégia de negócios, pode representar distintas abordagens e execuções. Num mundo mutável como em 
que vivemos, esse significado ampliou-se. Em uma empresa, como também na sociedade, esse termo está muito ligado aos conceitos de preservação do meio ambiente em benefício das gerações futuras, ao desenvolvimento social e as questões de governança, essa última abrigando a gestão econômicofinanceira. A instituição precisa de lucro para continuar no mercado e para manter os investimentos para seu crescimento. Alinhar processos com a visão corporativa e sua cultura, ter indicadores que validem os resultados e manter metas tangíveis e revisitá-las de maneira crítica, contribuem para que o planejamento estratégico se concretize. Mesmo em questões básicas como manter a contabilidade dentro dos critérios de boas práticas internacionais, validadas por auditoria externa, traz transparência, estabilidade e eficiência ao negócio, e faz crescer sua reputação. O acesso ao conhecimento para propiciar o crescimento contínuo é um campo fértil para as inovações. Treinamentos constantes, na área de atuação e em novas habilidades são estímulos para se ter um time sempre engajado e para, de fato, sustentar o crescimento da Instituição. Além disso, ter um olhar social, retribuir a sociedade os bons resultados é sustentabilidade no seu conceito mais nobre. Investimento em tecnologia da informação conduz a empresa para um mundo que não para de se reinventar, e ser protagonista nas mudanças, trazendo soluções inovadoras, é o caminho para diminuir custos, otimizar processos com aumento da eficiência e segurança. Na atualidade, para ser sustentável é preciso responder a três questões de fundo: a) qual é de fato o nosso negócio, b) como nós funcionamos, e c) como nos renovamos continuamente. Renovar e inovar são os fundamentos mais importantes para a sustentabilidade econômico-financeira. As melhores e mais eficientes empresas respiram inovação, e é nesse ecossistema que são criadas as melhores soluções com os melhores resultados.

Para ser competitivos, precisamos nos tornar sustentáveis. Em saúde, o atual desafio para se manter é conhecer seus custos, para que se possam reduzi-los sem prejuízo na entrega. Esse é o grande desafio para ser competitivo: agregar valor à entrega.

\section{Gestão adaptativa e ágil}

A pandemia mostrou a todos os setores produtivos a necessidade de se ter uma gestão ágil e adaptativa. Gestão ágil é uma nova forma de pensar e gerir as empresas, mas não significa que não existam planos ou governança. Ela diz respeito ao uso de qualidades distintas que permite às empresas responder rapidamente a mudanças, interna e externamente, sem perder o seu direcionamento e visão.

O setor de saúde foi especialmente afetado, com aguda redução nas receitas, necessidade de investimentos tecnológicos e em pessoas, adequação de processos e um cenário de incertezas. Os serviços que prestam atendimento ao Sistema Único de Saúde - SUS, sofreram interferência das secretarias de saúde de cada município que, na sua maioria, permitiram apenas o atendimento de casos considerados de urgência. 
Todas as instituições relacionadas a prestação de serviços em saúde, em toda a sua cadeia de produtividade e seus "stakeholders" precisaram sentar-se a mesma mesa para que fosse criado um plano de contingências e sustentabilidade social e econômica. Indicadores, metas e prazos foram revisitados e revisados continuamente, com um intervalo de tempo bem mais curto.

\section{Planejamento estratégico e liderança}

Nos últimos 10 anos, tornou-se perceptível a necessidade de iniciar um movimento de profissionalização da gestão em saúde. No cenário de crescente complexidade de processos e mudanças cada vez mais rápidas, o número de instituições que adotaram programas de gestão de liderança, qualidade e inovação vem aumentando exponencialmente.

Planejamento estratégico é a base de todo o processo de gestão empresarial. Com ele, são definidos todos os objetivos, metas e seus indicadores. Em geral, os principais objetivos são alcançados a longo prazo. Portanto, é importante definir metas que têm natureza intermediária em termos de tempo e alcance desse resultado esperado.

Os indicadores precisam ser específicos, mensuráveis, alinhados e tangíveis.

Pensando o setor de saúde como negócio, nos tempos atuais, sua estratégia para sustentabilidade a longo prazo é direcionada em transformar e criar valor em saúde com foco no paciente.

Os gestores em saúde promovem:

- Planejamento: com a definição dos objetivos estratégicos da empresa e dos planos de ações

- Organização: criação de estrutura e mecanismos que serão responsáveis pela execução de planos de ações e alocação de recursos disponíveis

- Controle: coordenar e orquestrar as ações e projetos, aos quais se destacam os papeis e responsabilidades da liderança

- Direção: monitoramento das ações executadas na busca dos objetivos estratégicos. Os indicadores de desempenho são utilizados nesse momento

As ferramentas para construção do planejamento estratégico têm como elementos a análise dos cenários interno e externo, sendo que esse último tem como perspectiva o macro ambiente político, econômico, social, legal e tecnológico. No cenário interno é possível identificar as forças e fraquezas. Esses fatores são controláveis e manejáveis, ao contrário dos fatores externos. 
Ainda na construção do planejamento estratégico em saúde, deve-se considerar que indicadores de desempenho que medem resultados são primordiais. Entretanto, os indicadores que medem desfechos na linha de cuidados se tornam cada dia mais importantes.

Juntamente com o planejamento estratégico, torna-se necessário construir a capacidade de liderança da empresa, que é referente às atividades de identificação das competências críticas dos líderes, do alinhamento com os valores, dos cargos críticos para a gestão do negócio e dos riscos envolvidos com as prioridades estratégicas do negócio. É uma "auditoria das capacidades de liderança". É perguntar-se: temos um time qualificado, alinhado e comprometido para enfrentar os desafios do contexto de negócios a frente?

Trata-se também da construção de uma estrutura organizada, com uma descrição clara das áreas de atuação, com responsabilidades, com linhas de autoridade e com coordenação bem definida, e a escolha de líderes habilidosos para a condução de suas áreas que atendam aos papéis definidos. A interdisciplinaridade estimula a integração e cooperativismo entre as equipes conduzidas e estimuladas pelos líderes.

O alinhamento dos objetivos entre a alta gestão, as lideranças e os liderados precisam estar consolidados e incorporados à cultura da empresa. $\mathrm{A}$ isso, denomina-se propósito.

\section{Propósito, cultura, visão e ação}

Nesse ponto, voltam à tona perguntas como: Qual de fato é o nosso negócio? Quem somos? E por que fazemos o que fazemos?

O propósito define a razão central de existirmos como organização e o impacto positivo que temos na sociedade. Ele influencia a estratégia, inspira nosso pessoal, engaja nossos clientes e comunidades, direciona escolhas em momentos críticos e está completamente integrado na cultura.

As empresas, de modo geral, vêm sendo construídas com bases na entrega: "o que".

Entretanto, estudos revelam que as empresas que se consolidam são construídas baseadas no "porque".

O propósito é a cultura da empresa, é o alicerce e ponto de partida.

Não menos importante é o "como". O "como" são os processos que são conduzidos pelas pessoas.

Nesse ponto, entendemos o quanto se faz primordial a incorporação da cultura entre toda a cadeia de pessoas.

É atingido o conceito da a missão e dos valores dessa empresa. O "o que" será respondido pela visão. 
O propósito fundamenta a visão de futuro para sabermos aonde se quer chegar. Para conduzir a instituição ao crescimento contínuo, é necessário estar atento aos movimentos do mercado. Ou seja, em um mundo onde as mudanças são cada vez mais rápidas, os indicadores de cada um dos setores precisam ser monitorados por meio de sistemas de informação on time. 0 desejado é ser sempre o foco, e escolher a estratégia dentro da própria cidade, do estado e do país é um grande desafio. Ter esse crescimento de maneira perene significa ter escolhas que trazem resultados, que dos parceiros, com quem é necessário unir as forças, faz toda a diferença. Tudo isso precisa estar consolidado num conjunto de ações de curto, médio e longo prazos que são executados com muita disciplina.

No caso da área de saúde, nossos clientes são os próprios médicos que utilizam a rede, os pacientes, os convênios, os parceiros comerciais (laboratórios, terceiros). Devemos entender cada cliente para que possamos estreitar a relação, trazendo um ambiente interessante para as duas partes, para trazer a tão almejada fidelidade do paciente.

Para exemplificar a complexidade desse tema, foi feita uma consultoria para classificar os clientes pacientes, com o objetivo de aumentar a assertividade na estratégia de marketing para cada público. $O$ resultado foi surpreendente. Temos os clientes da urgência 24 horas, do atendimento ambulatorial, com consultas e exames, do bloco cirúrgico e da estética. Para cada setor um foco de atuação diferente. Para o cliente da urgência e do ambulatório, temos que focar em processos de excelência: rapidez no atendimento, localização, ampla rede de convênios, limpeza, preço, qualidade dos profissionais, ou seja, a capacidade de resolução do problema. Para o cliente do bloco cirúrgico, o foco era o produto, o melhor bloco cirúrgico oftalmológico da cidade: estrutura, equipe e eficiência. E para o cliente da estética, o resultado entregue é o foco. Logo, o cliente paciente fornece várias estratégias a serem planejadas, com resultados totalmente diferentes.

Já em relação ao cliente médico, a gestão de corpo clínico é uma valiosa ferramenta. Os indicadores foram alinhados entre a alta gestão, diretoria clínica e representantes do corpo clínico, e a participação dos médicos passa a ser muito relevante para o engajamento deles. A melhoria técnica de toda a cadeia de atendimento traz a excelência ao paciente, proporcionando a maior assertividade possível do tratamento e aumentando a fidelidade do médico à instituição.

Todos os processos na cadeia de atendimento são importantes para tornar a visita do paciente numa encantadora experiência. Tudo impacta. Desde a marcação com eficiência, até a resolução no desfecho. Marcar com agilidade, dar relevância às necessidades do paciente e compreender quais são os procedimentos solicitados, faz com que um momento de fragilidade do paciente se torne uma experiência de acolhimento. Além disso, clareza nas informações e cordialidade transmitem ao paciente uma percepção de empatia e segurança.

O atendimento médico pontuado na ética, utilização racional da tecnologia e adesão a protocolos promovem maior efetividade na linha de cuidado e monitoramento de desfecho. 
Dentro da cadeia de atendimento, contarmos com um robusto sistema de prontuários e gestão se torna primordial. O investimento em uma equipe de tecnologia da informação é indispensável para que o sistema escolhido seja esgotado em suas funcionalidades e propriedades. A integração de dados promove o acompanhamento de painéis de gestão em tempo real e fornece à alta gestão cenários e oportunidades de melhorias e planejamento de ações assertivas com agilidade e confiabilidade.

Na prática médica, a integração de equipamentos de imagem e diagnóstico com os prontuários promove o armazenamento seguro e organizado dos documentos. Além disso, através do acesso remoto, médicos podem, de maneira ágil, gerar laudos e liberar exames. Dessa maneira, os pacientes terão o acesso a isso tudo de maneira rápida e segura.

A criação do banco de imagens promove a expansão da coleta de dados e proporciona maior oportunidade para realização da medicina acadêmica.

A pandemia tornou a telemedicina uma realidade. Esse método de atendimento remoto, já amplamente discutido no meio médico, ainda apresentava gargalos. A pandemia foi um catalisador para que as adequações tornassem viável esse tipo de atendimento, e tornou-se indiscutível como as consultas remotas trouxeram benefícios à sociedade, sendo uma importante ferramenta para médicos e pacientes e familiares no controle de doenças crônicas, monitoramento dos pacientes e abordagem nas doenças mentais.

Muito há que ser construído, normatizado e desenvolvido nessa nova modalidade de atendimento, porém é que esse modelo já está incorporado às práticas assistenciais.

\section{Concluindo}

Para que a empresa e o negócio sejam sustentáveis, tudo isso tem que estar direcionado para um resultado positivo. Os resultados financeiros, como lucro e retorno ao investimento, são, muitas vezes, confundidos pelo formato de várias instituições na área da saúde, já que os honorários médicos nem sempre são somados ao resultado da empresa. Muitas vezes, os próprios médicos não percebem como é importante manter a "galinha dos ovos de ouro" saudável, ou seja, a empresa. Essa confusão é percebida na compra de cotas ou ações da clínica pelo médico, que não é apenas um local de trabalho e sim uma empresa, onde pode e deve haver retorno do investimento. O fluxo de caixa da empresa é muitas vezes confundido com lucro e traz problemas sérios à saúde financeira, quando se necessita de um investimento ou mesmo a cobertura de um imprevisto, quando aquele é usado de maneira inadvertida. Ao mesmo tempo, a dedicação do profissional de saúde é tamanha, que vale muito mais um hospital equipado e moderno que um resultado financeiro positivo. A saúde do paciente é mais importante que o valor recebido. Outra característica muito comum dos profissionais de saúde é a priorização autopromoção em sobre a da empresa. Autoestima elevada, ou amor exagerado pelos próprios interesses, gera uma dificuldade muito grande de trabalhar em equipe. Muito 
provavelmente, um ou mais de um desses fatores foi e vem sendo responsável pelo fechamento várias empresas de saúde. Outros pontos que dificultam o resultado positivo são as negociações com os laboratórios e com as empresas de saúde suplementar. Normalmente as clínicas são prejudicadas, pagando muito pelos insumos e recebendo cada vez menos dos convênios, que, além disso, fazem fluxo de caixa com esse dinheiro, pagando as clínicas até 90 dias depois. Um bom gestor faz com que tudo isso se conecte e finalize com indicadores que demonstram metas atingidas, levando a números positivos. Resultados sustentáveis associados à boas práticas preparam as empresas para tempos de crise, como a causada atualmente pelo coronavírus, e preparam para novos desafios. Então, é introduzido o mercado de aquisições e fusões, que está superaquecido, principalmente na oftalmologia. Para que as empresas recebam atenção dos fundos de investimentos precisam mostrar um resultado financeiro positivo. Com isso, recebem investimentos, trazendo um suporte financeiro ainda mais importante para o crescimento destas.

É importante ressaltar que a importância do resultado financeiro nas clínicas tem que ser semelhante aos resultados relativos as pessoas, resultados relativos a fornecedores, resultados relativos ao produto, à sociedade e aos processos de apoio e de organização.

Atualmente, todos esses resultados serão mais facilmente atingidos quando um dos principais valores for a inovação. Esta, mais do que nunca, tornou-se uma ferramenta fundamental nas empresas. As soluções são mais facilmente encontradas quando a inovação é implementada numa organização. Em um mundo onde a velocidade de mudança se tornou um indicador de sustentabilidade, as empresas que inovam se preparam melhor para os novos tempos. Além de prever as mudanças que vão ocorrer, é possível ser agente dessas mudanças. O ensino eleva o patamar dos profissionais que trabalham na empresa e traz uma visibilidade positiva a todos que fazem parte do processo. Com um ensino de alto nível, automaticamente a pesquisa se faz necessária, para organizar todo aprendizado, todo ensino e passar para a comunidade cientifica novas informações relevantes, trazendo para o mundo novos ensinamentos.

Dessa forma, conclui-se que, para se fazer gestão em empresas da área de saúde, especificamente em oftalmologia, todos os envolvidos têm que estar realmente engajados, fazer tudo com muita responsabilidade, trazendo novas soluções para se preparar para um mundo cheio de alternativas e que muda numa velocidade nunca vista. O legado de cada empresa é único. Na saúde, temos a obrigação de transformar para melhorar a vida das pessoas. Curar nem sempre é possível; confortar, sim; porém, transformar é para poucos. A busca pela excelência faz os resultados serem mais sólidos, o crescimento é status quo, e a tão esperada sustentabilidade vem de maneira real e definitiva.

\section{REFERÊNCIAS}

1. Scarpi M J. Gestão de Clínicas Médicas. São Paulo: Editora Futura; 2004. 
2. Pádua Filho W. Inovação é tudo. São Paulo: Atlas Editora; 2015.

3. Scott C D, Jaffe D T, Tobe G R. Visão, Valores e Missão Organizacional, Construindo a Organização do Futuro. Rio de Janeiro: Qualitymark; 1998.

4. Centurion V. As bases da Administração em Oftalmologia. São Paulo: Editora Cultura Médica; 2001.

Recebido: 8 de abril de 2021. Aceito: 28 de maio de 2021

Correspondência: Claudio Augusto Junqueira de Carvalho. E-mail: cqh@apm.org.br

Conflito de Interesses: o autor declarara não haver conflito de interesses

(C) This is an Open Access article distributed under the terms of the Creative Commons Attribution License, which permits unrestricted use, distribution, and reproduction in any medium, provided the original work is properly cited 